\title{
Probing Stepwise Complexation in Phenylazomethine Dendrimers by a Metallo-Porphyrin Core.
}

Takane Imaoka ${ }^{1}$, Reiko Tanaka ${ }^{1}$, Sachiko Arimoto ${ }^{1}$, Makoto Sakai ${ }^{2}$, Masaaki Fujii ${ }^{2}$ and Kimihisa Yamamoto ${ }^{1 *}$

${ }^{1}$ Department of Chemistry, Faculty of Science and Technology, Keio University

${ }^{2}$ Chemical Resources Laboratory, Tokyo Institute of Technology

E-mail: yamamoto@chem.keio.ac.jp

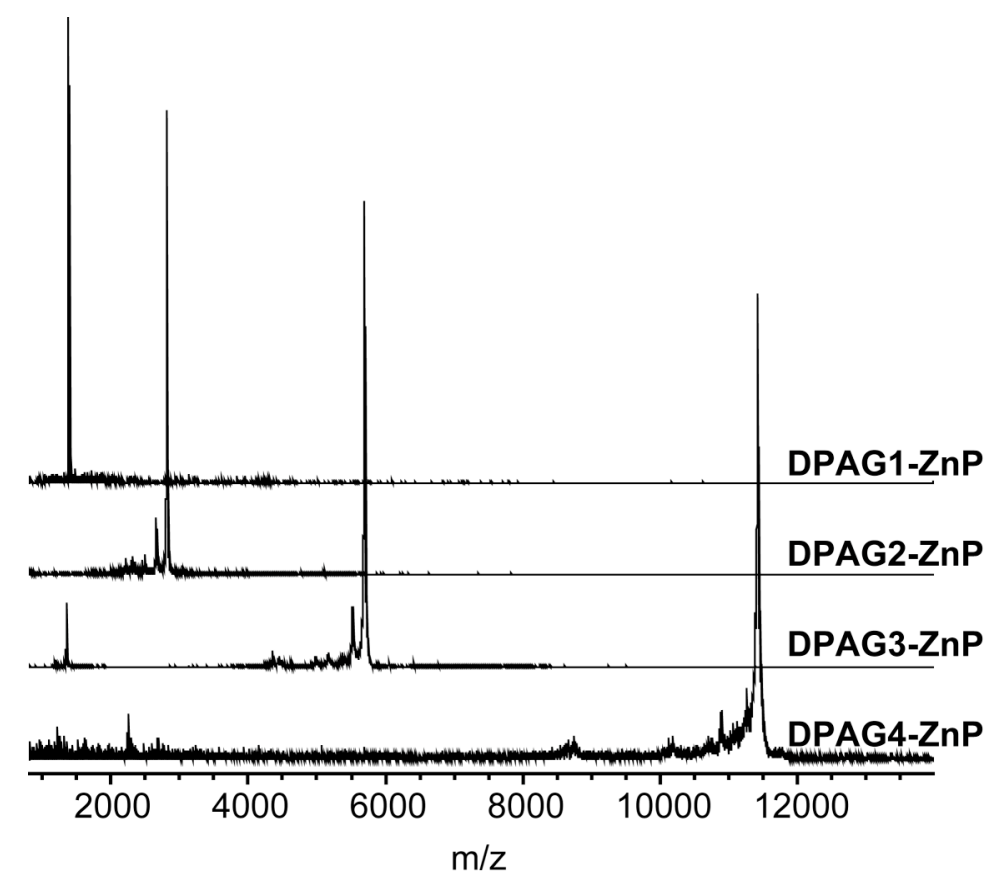

Figure S1. MALDI-TOF-Mass spectra of the DPAGX-ZnP. 


\section{Supporting Information}

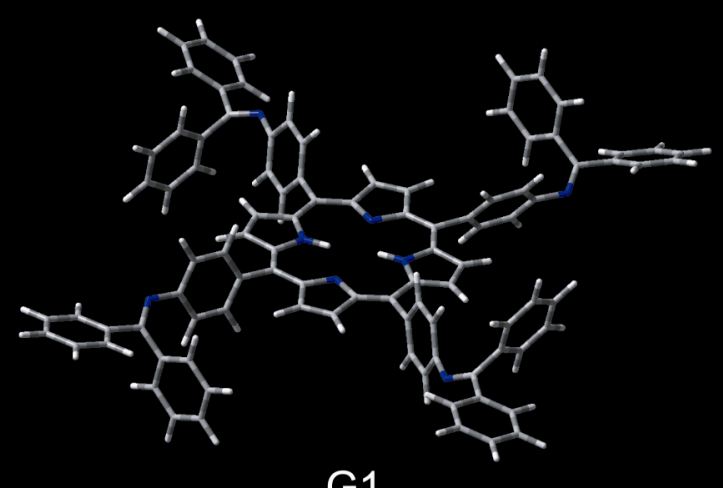

G1
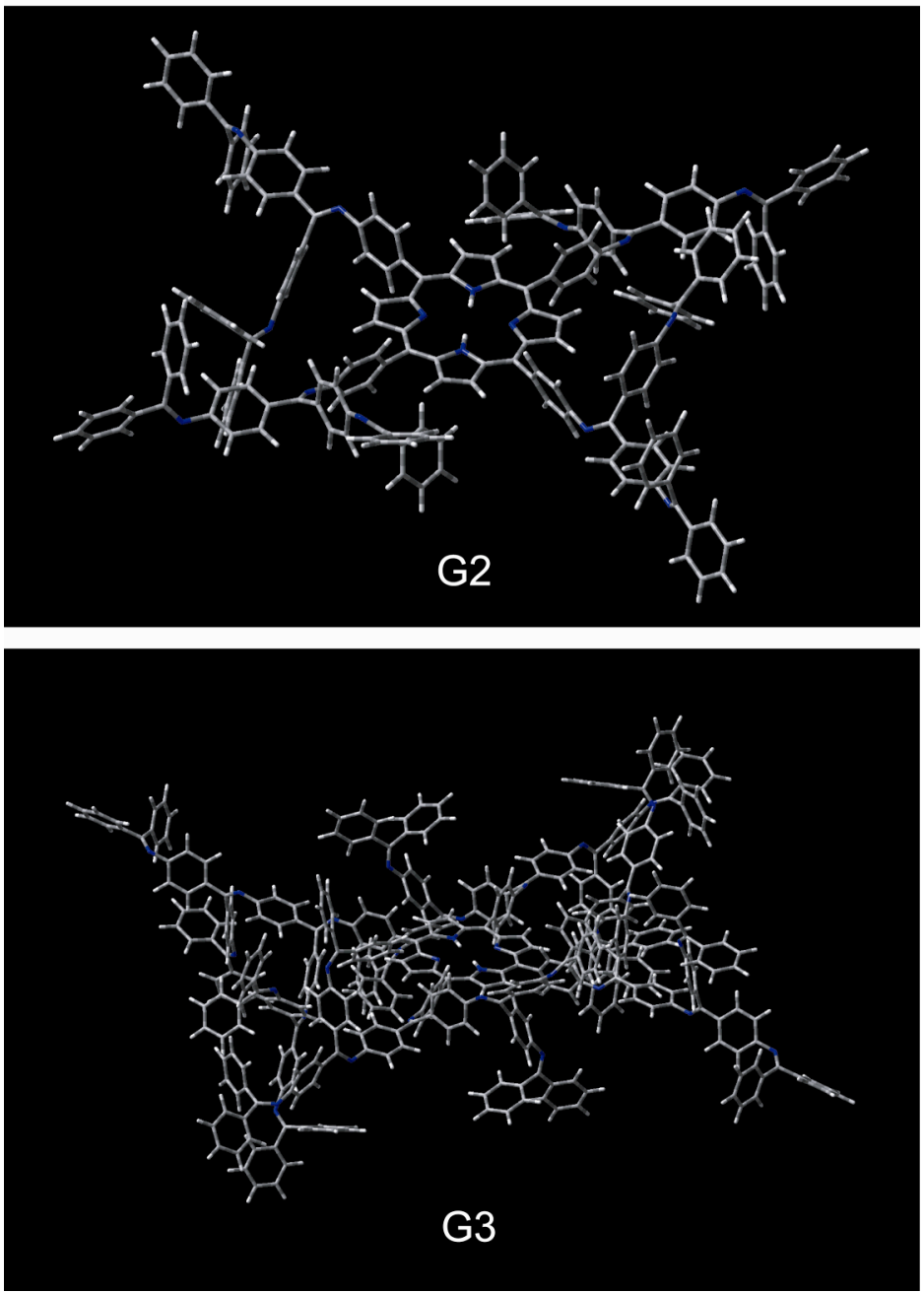

Figure S2. 3D models of DPAGX-H $\mathbf{H}_{2} \mathbf{P}(\mathrm{X}=1 \sim 3)$ optimized by MOPAC (AM1) calculations. 


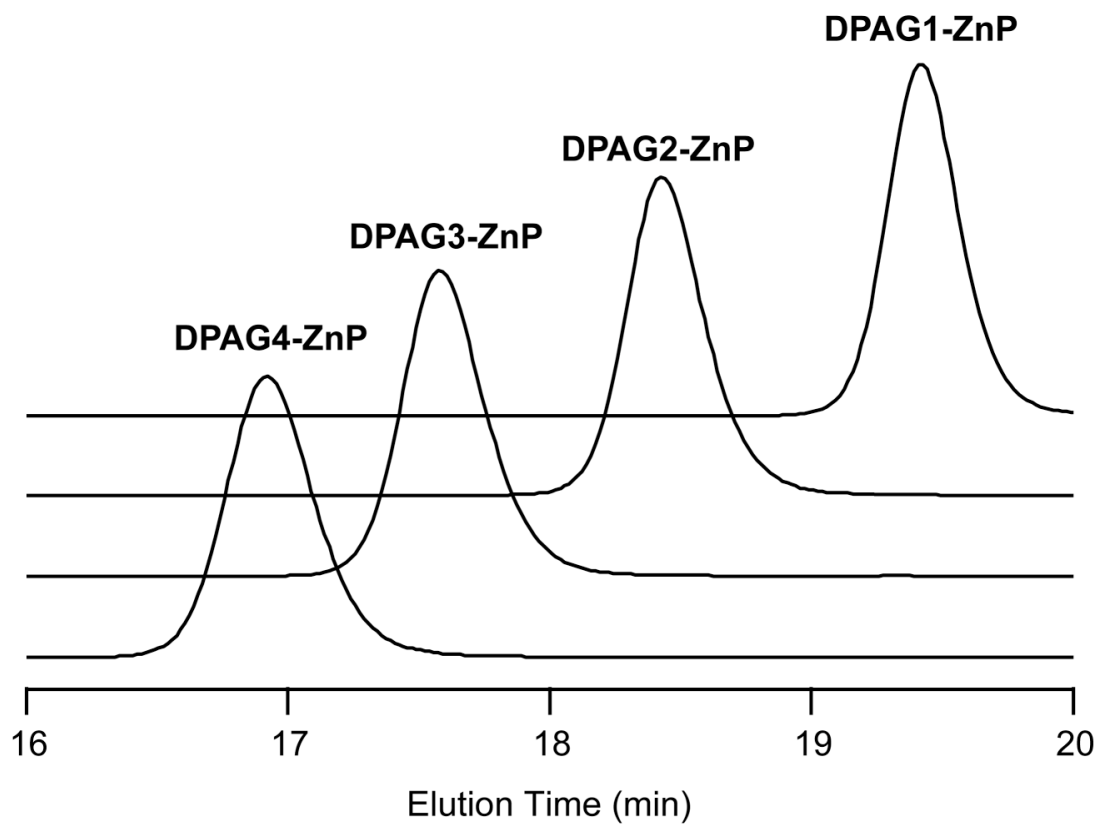

Figure S3. Elution curves of SEC measurements (DPAGX-ZnP) by an RI detector. THF was used as the eluent at a flow rate of $1 \mathrm{ml} / \mathrm{min}$.

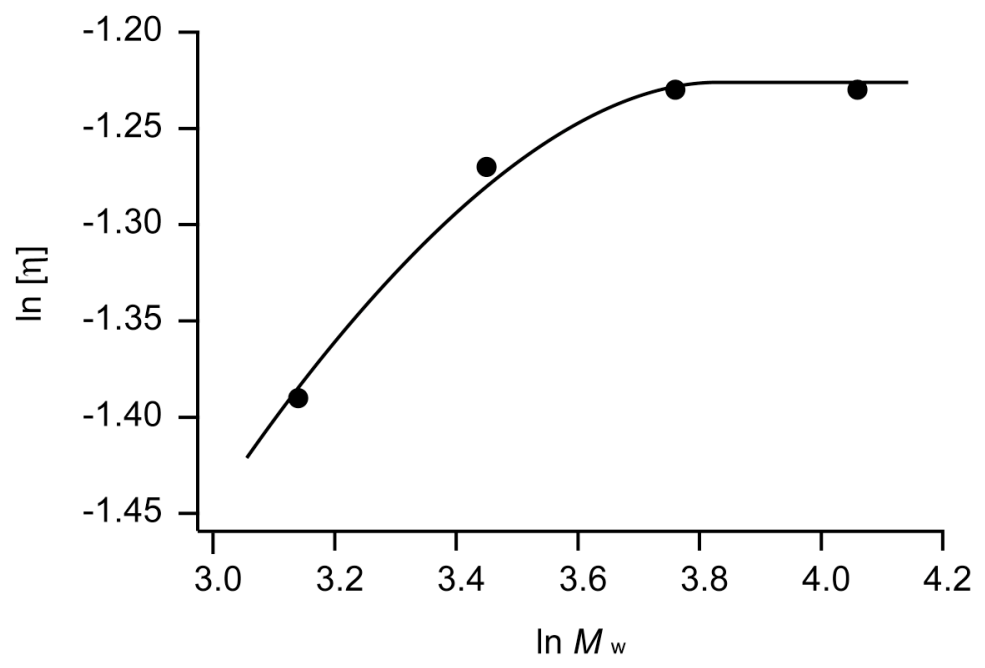

Figure S4. Mark-Howink plot of DPAGX-ZnP in THF. 


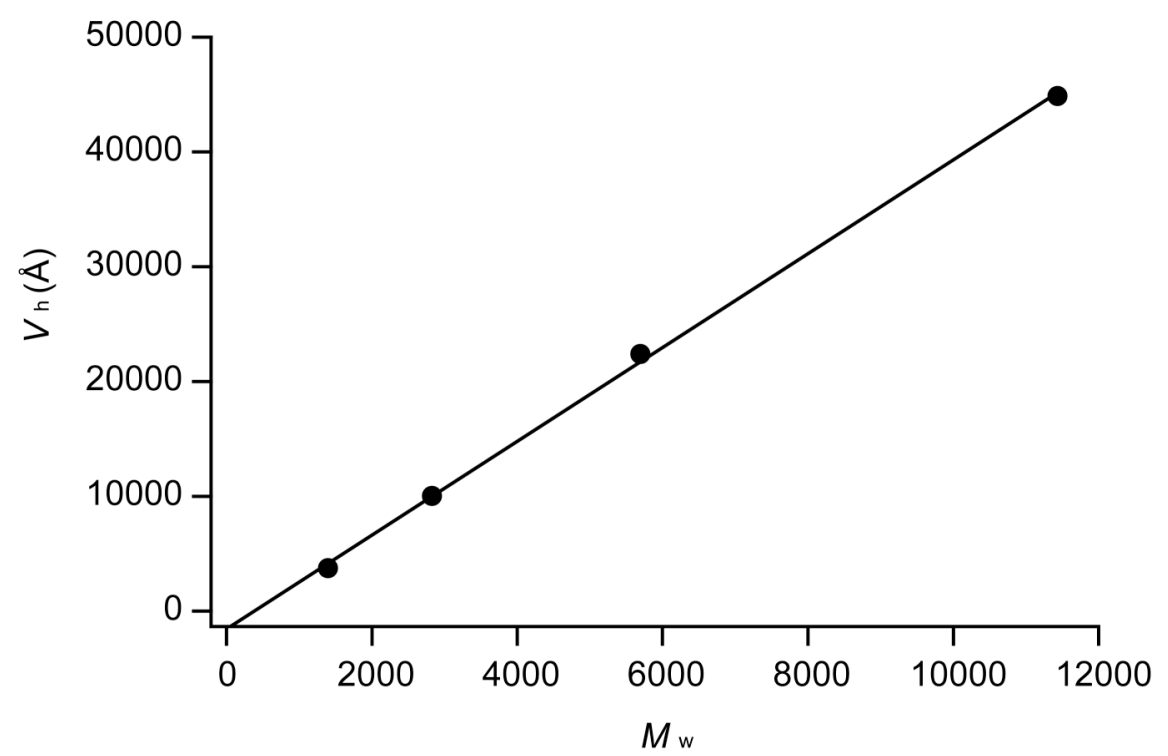

Figure S5. Relationship between the molecular weight $\left(M_{\mathrm{w}}\right)$ and the hydrodynamic volume $\left(V_{\mathrm{h}}\right)$ of DPAGX-ZnP $(X=1 \sim 4)$.

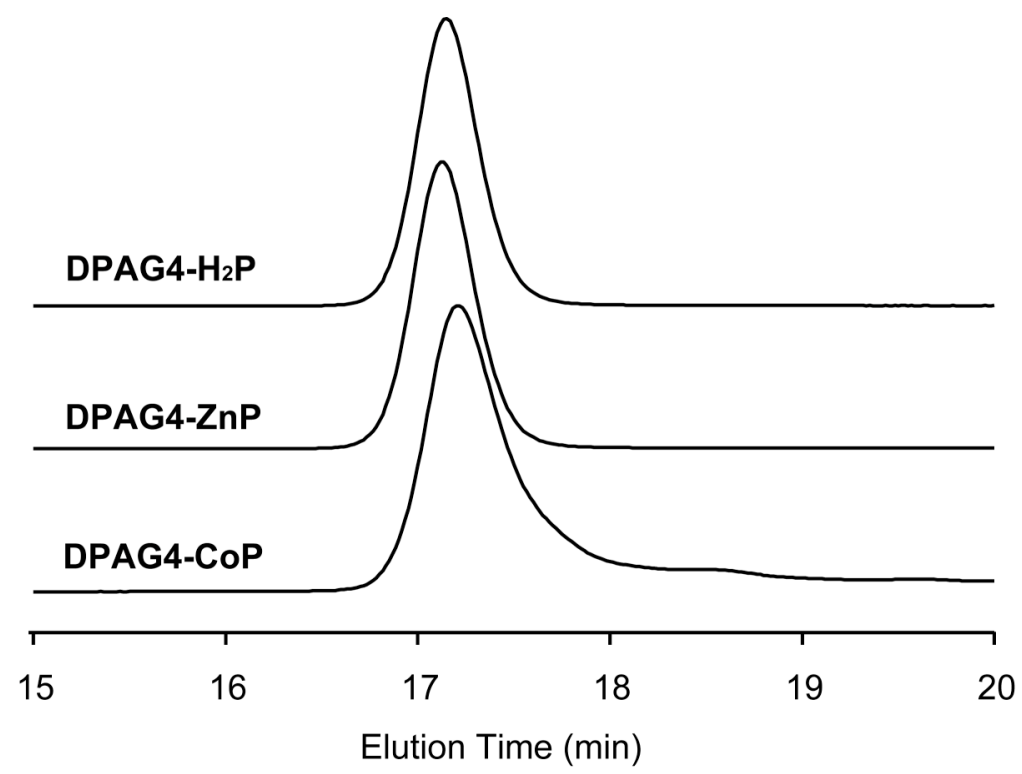

Figure S6. Elution curves of SEC measurements (DPAG4-H2P, DPAG4-ZnP, DPAG4-CoP) by an RI detector. THF was used as the eluent at a flow rate of $1 \mathrm{ml} / \mathrm{min}$. 


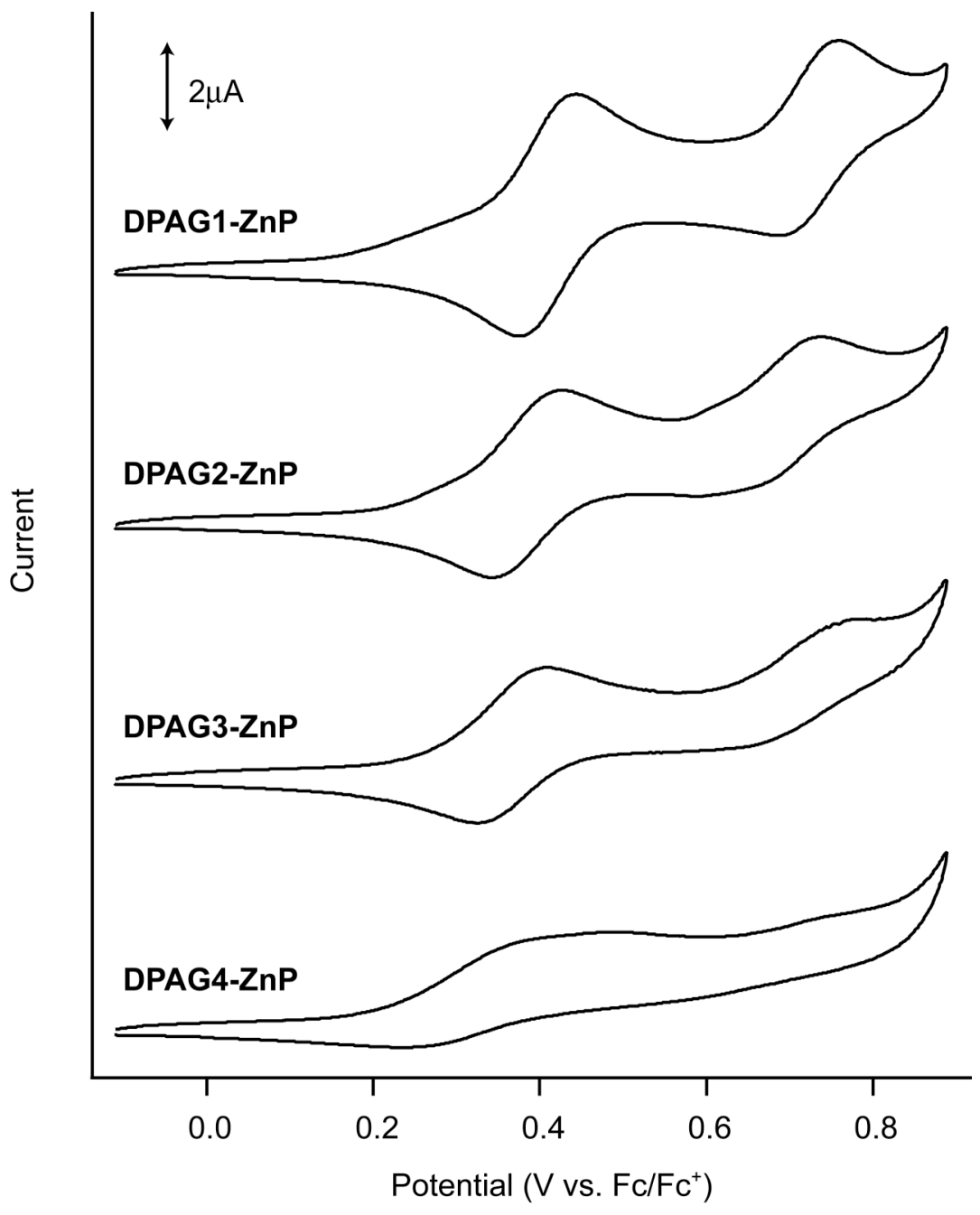

Figure S7. Cyclic voltammograms of DPAGX-ZnP $(X=1 \sim 4)$ in $\mathrm{Bu}_{4} \mathrm{NPF}_{6}(0.1 \mathrm{M}) /$ THF solution.
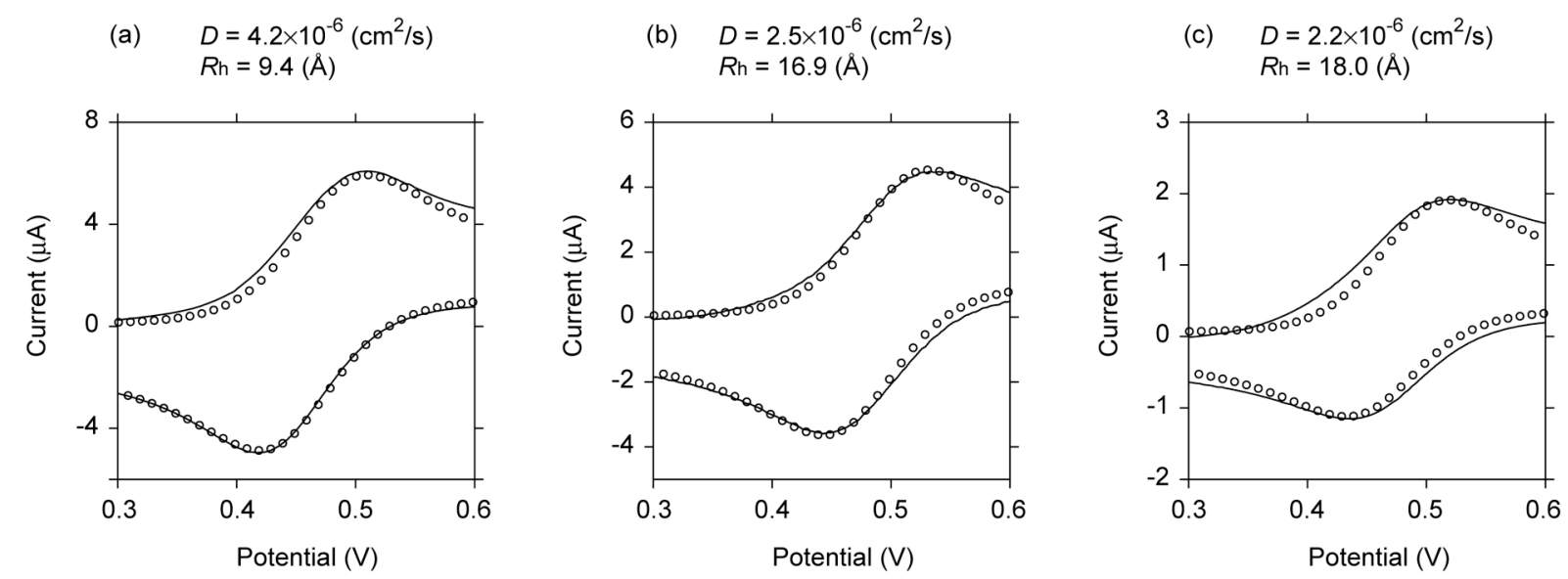

Figure S8. Cyclic voltammograms of (a) DPAG1-ZnP, (b) DPAG2-ZnP, (c) DPAG3-ZnP measured in $\mathrm{Bu}_{4} \mathrm{NPF}_{6}(0.1 \mathrm{M}) / \mathrm{THF}$ solution at $20 \mathrm{mV} / \mathrm{s}$ of the scan rate. White circles are the simulated cyclic voltammograms by Digi-Sim using the diffusion constants $(D)$ shown in the figure. 


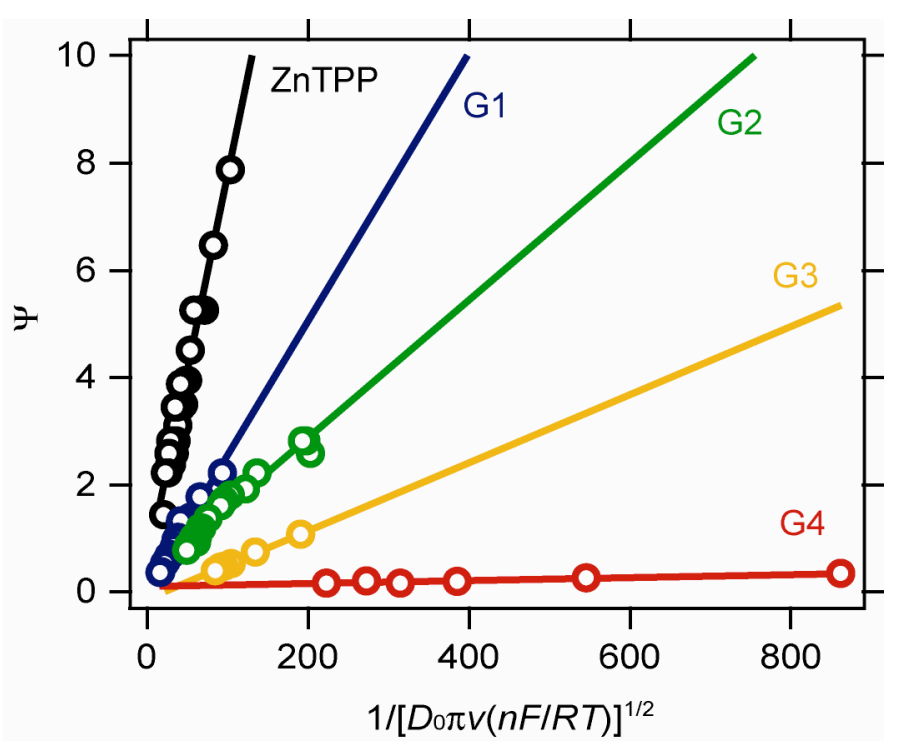

Figure S9. Nicholson plots of the $\mathrm{ZnP} / \mathrm{ZnP}^{+}$redox couple of DPAGX-ZnP for determination of the electron transfer rate constant $\left(k_{0}\right)$ on the electrode (GCE) surface. The cyclic voltammograms were obtained by $I R$ drop compensation using positive feedback method. 

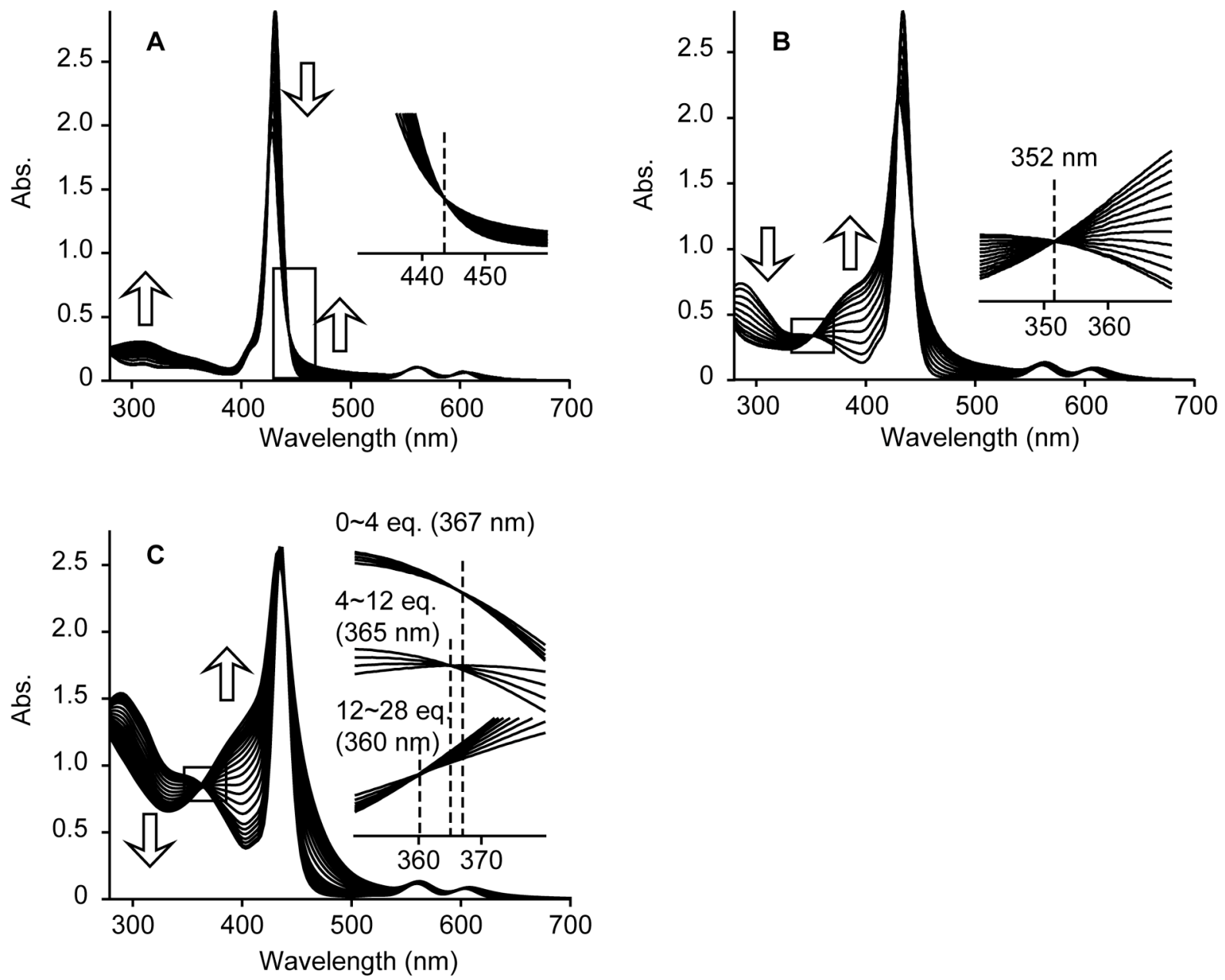

Figure S10. UV-vis spectra changes upon the addition of $\mathrm{SnCl}_{2}$ to DPAG1-ZnP (A), DPAG2-ZnP (B) and DPAG3-ZnP (C) solution in $\mathrm{C}_{6} \mathrm{H}_{6} / \mathrm{MeCN}(1: 1)$, (Inset) enlargements of the isosbestic points.
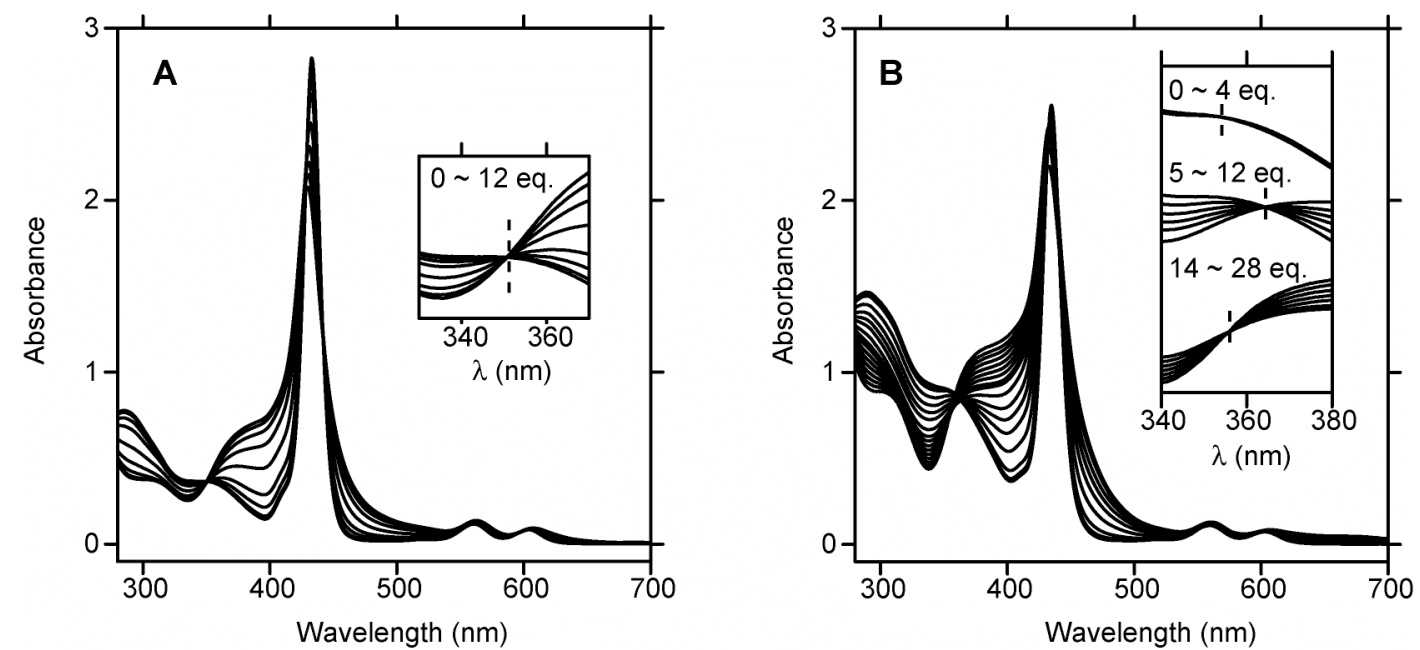

Figure S11. Subtracted UV-vis spectra changes upon the addition of $\mathrm{FeCl}_{3}$ to $5 \mu \mathrm{M}$ DPAG2-ZnP (A) and DPAG3-ZnP solution in $\mathrm{C}_{6} \mathrm{H}_{6} / \mathrm{MeCN}$ (1:1), (Inset) enlargements of the isosbestic points. 


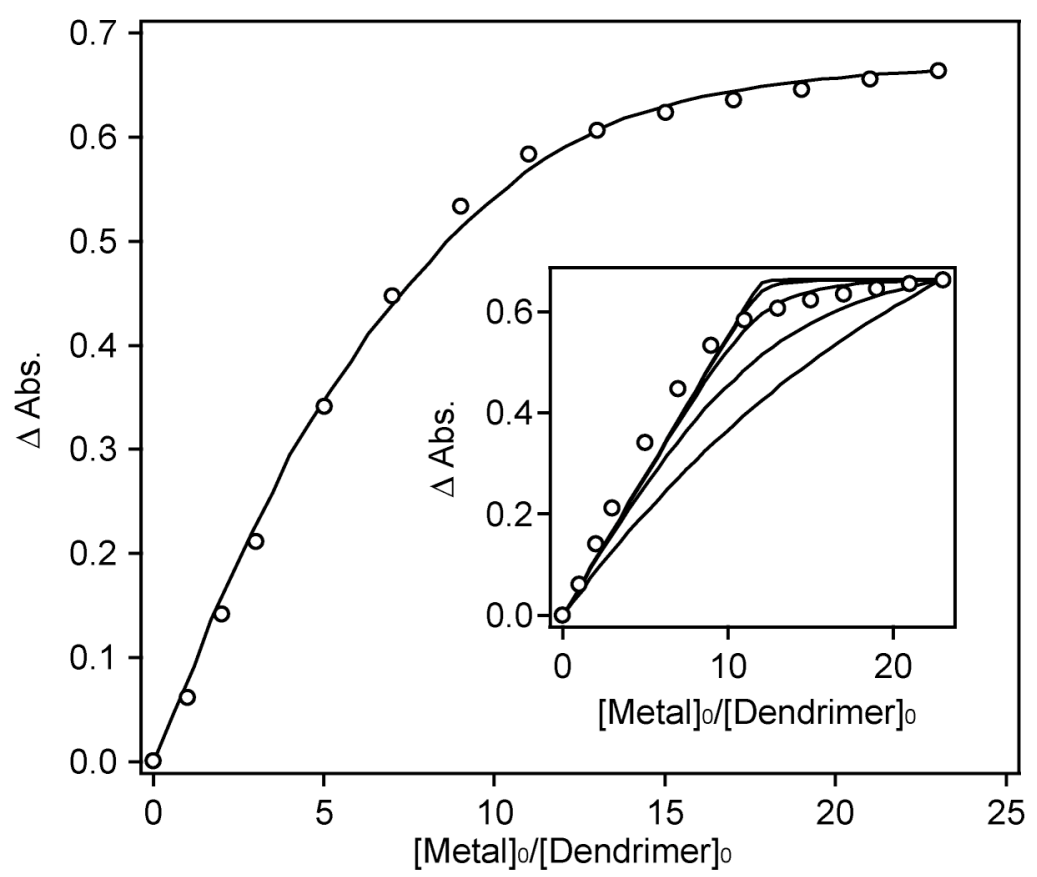

Figure S12. Absorbance change at $400 \mathrm{~nm}$ upon the addition of $\mathrm{FeCl}_{3}$ to DPAG2-ZnP. The solid line is a calculated profile based on the theoretical equilibrium model involving two independent reactions $\left(K=5.0 \times 10^{6}\left[\mathrm{~mol}^{-1} 1\right]\right.$ and $\left.2.5 \times 10^{5}\left[\mathrm{~mol}^{-1} 1\right]\right)$. Inset figure shows the same plots fitted by theoretical model assuming only one equilibrium reaction. This model cannot be fitted in experiment exactly.

(A)

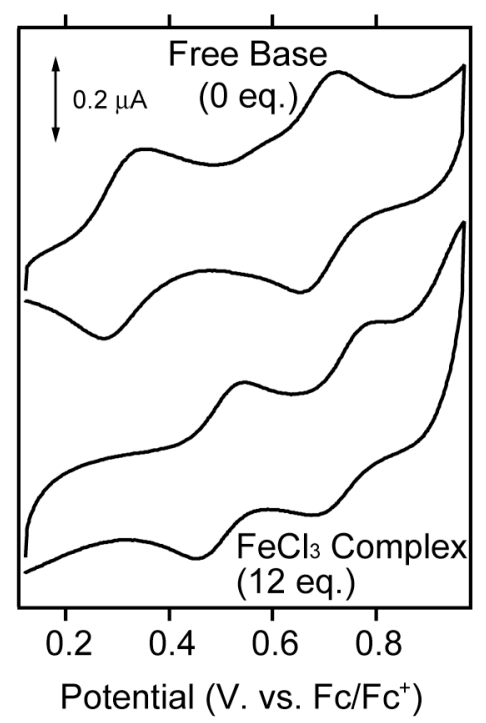

(B)

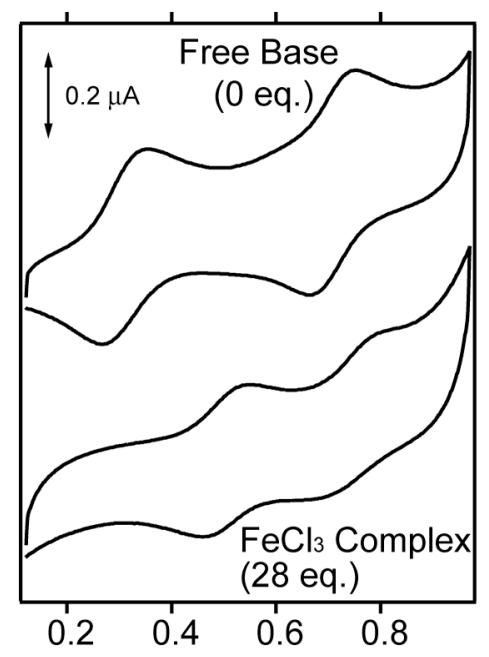

Potential (V. vs. Fc/Fc $)$
(C)

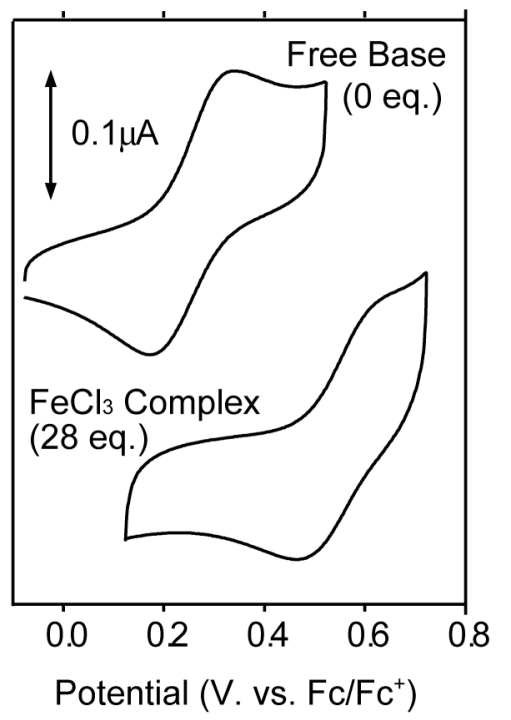

Figure S13. Cyclic voltammograms of (a) DPAG2-ZnP, (a) DPAG3-ZnP, (a) DPAG4-ZnP in the absence or presence of $\mathrm{FeCl}_{3}$ in $\mathrm{CHCl}_{3} / \mathrm{MeCN}$ (4:1) solution with $0.1 \mathrm{M} \mathrm{Bu}_{4} \mathrm{NPF}_{6}$ at $20 \mathrm{mV} / \mathrm{s}$ of the scanrate. 

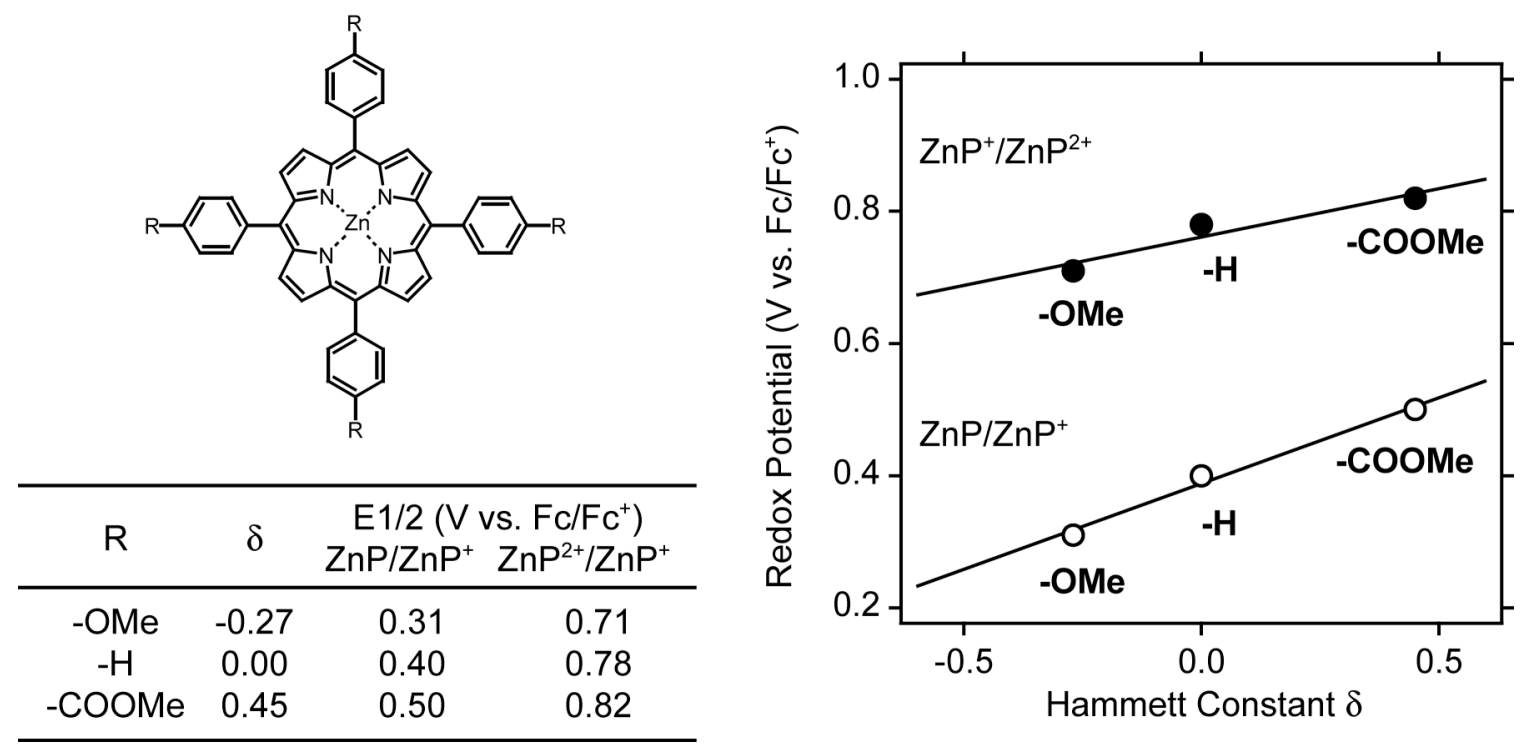

Figure S14. A relationship between the redox potential of $1 \mathrm{e}^{-}$oxidations and Hammett constants of the para-substituents within zinc meso-tetraphenyl porphyrin in THF.

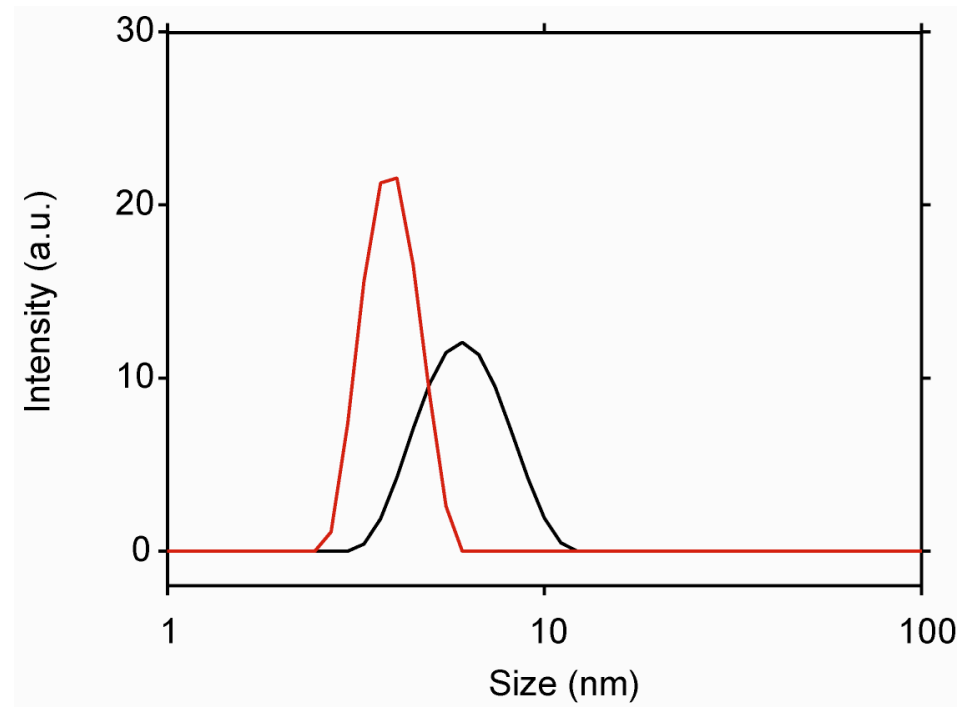

Figure S15. Profiles of the molecular size for DPAG4 measured by dynamic light scattering (DLS) method. Red line corresponds to the complex with $\mathrm{FeCl}_{3}$ (28 eq.), while the black line is the free base one. 

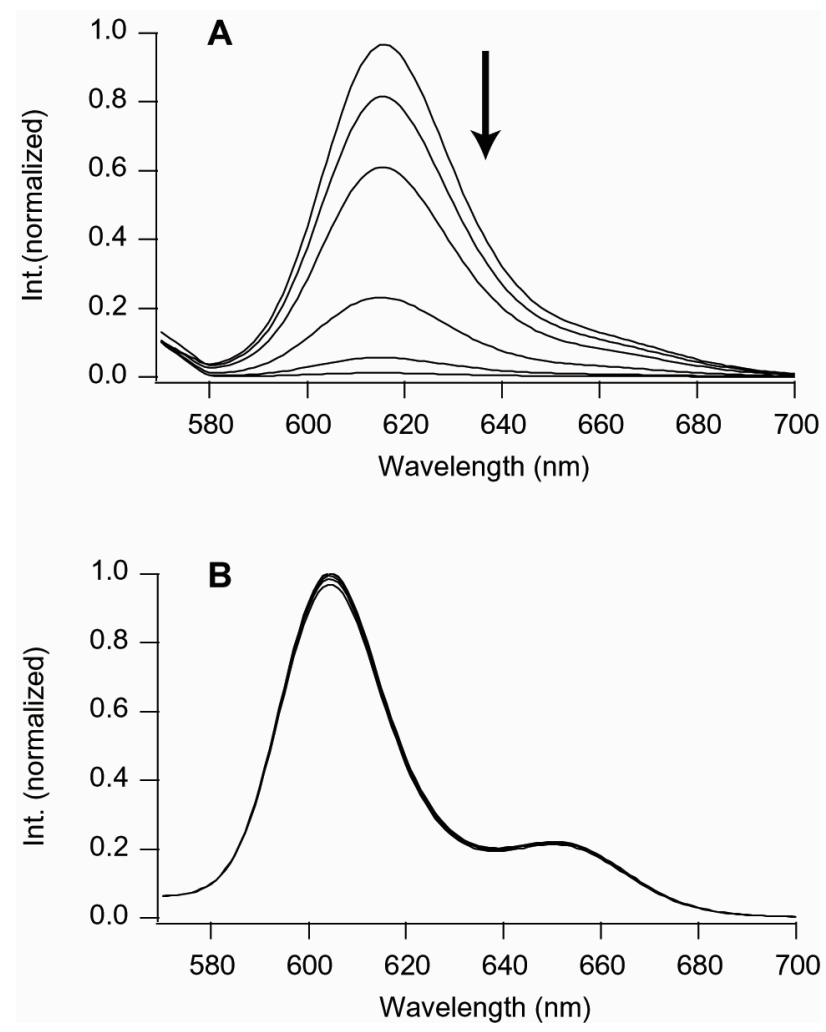

Figure S16. Fluorescence spectra of (A) DPAG2-ZnP (10 $\mu \mathrm{M})$ and (B) zinc tetraphenylporphyrin (10 $\mu \mathrm{M})+$ DPAG2-Ph $(40 \mu \mathrm{M})$ upon the addition of $\mathrm{FeCl}_{3}(0 \sim 4$ equivalents $)$ in $\mathrm{C}_{6} \mathrm{H}_{6} / \mathrm{MeCN}(1: 1)$. The excitation wavelengths are (a) $550 \mathrm{~nm}$ and (b) $564 \mathrm{~nm}$, respectively.

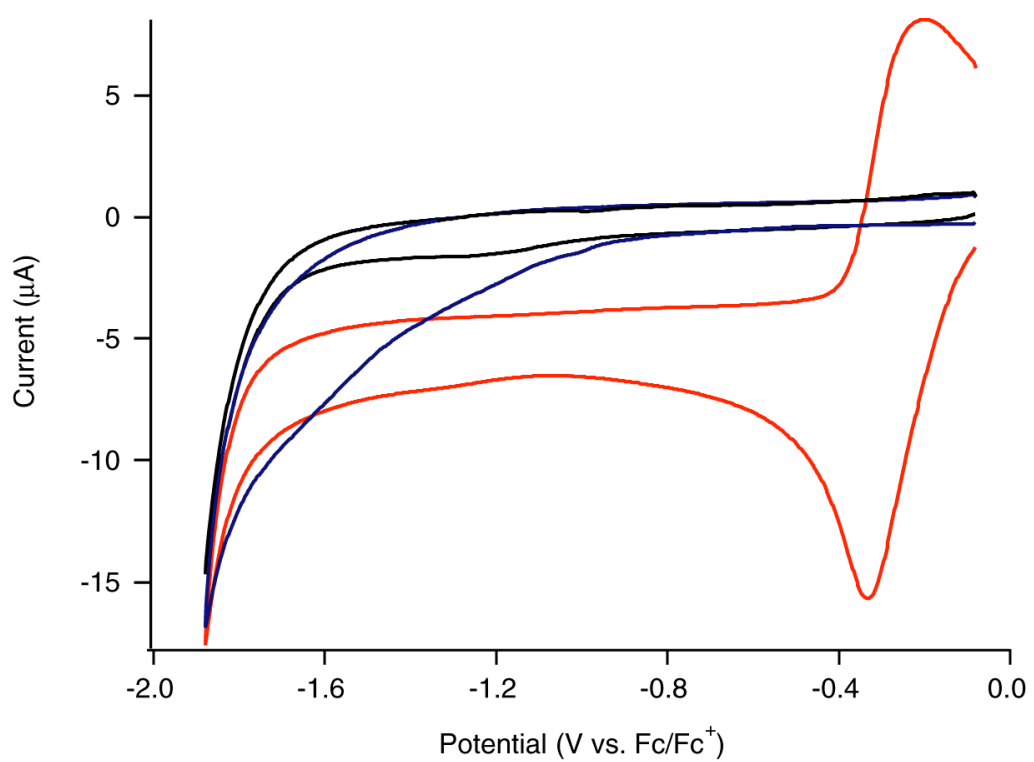

Figure S17. Cyclic voltammograms of $1 \mathrm{mM} \mathrm{FeCl}_{3}$ (red), $\mathrm{SnCl}_{2}$ (blue) and blank in $\mathrm{CHCl}_{3} / \mathrm{MeCN}(1: 1)$. $\phi$ $3 \mathrm{~mm}$ glassy carbon disk was used as the working electrode and $0.1 \mathrm{M} \mathrm{Bu}_{4} \mathrm{NBF}_{4}$ was used as the supporting electrolyte. 


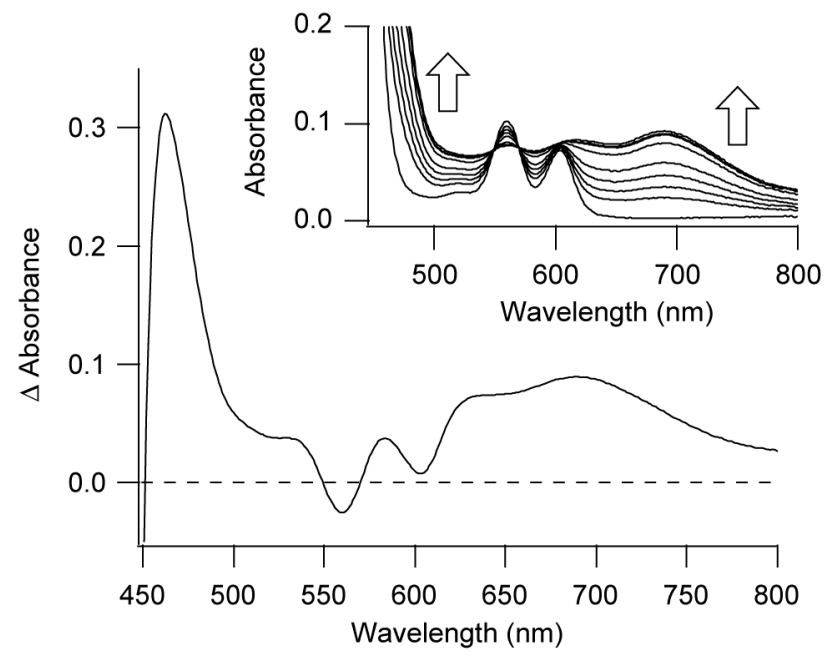

Figure S18. Different absorption spectra during the electrochemical oxidation of DPAG4-ZnP $(50 \mu \mathrm{M})$ at $0.55 \mathrm{~V}$ vs. $\mathrm{Fc}_{\mathrm{Fc}}{ }^{+}$in $\mathrm{C}_{6} \mathrm{H}_{6} / \mathrm{MeCN}$ solution. The inset figure shows the actural spectral changes during the oxidation. 